\title{
MEDIOS, NUEVOS MEDIOS TECNOLÓGICOS DE LA COMUNICACIÓN Y DE LA INFORMACIÓN Y NUEVAS IDENTIDADES DE GÉNERO ${ }^{1}$
}

\author{
Rita $M^{\mathrm{a}}$ Radl Philipp ${ }^{2}$
}

\section{RESUMO}

Este texto analisa o significado dos meios e dos novos meios tecnológicos da informação e da comunicação para com as identidades de gênero sob o ponto de vista teórico e epistemológico. De modo concreto analisaremos, em primeiro lugar, os conceitos de pósmodernismo, feminismo, meios e tecnología. Em segundo lugar, aprofundamos nas implicações epistemológicas dos postulados pós-modernistas e, por último, perfilamos os nossos argumentos segundo uma perspectiva sociológica educacional específica, explicando os processos de socialização e uso técnológico crítico-ideológico. De modo preciso defendemos uma atitude crítico-ideológica quanto ao uso tecnológico e seu significado a partir de uma ótica das identidades de gênero.

Palavras-chave: Gênero, Epistemología, Meios, Novas Tecnologías da informação, Socialização.

\section{RESUMEN}

Este texto enfoca el significado de los medios y de los nuevos medios tecnológicos de la información y comunicación para con las identidades de género bajo un prisma teóricoepistemológico. De modo concreto trataremos, en primer lugar, la temática postmodernismo, feminismo, medios y tecnología. En segundo lugar, profundizaremos en las implicaciones epistemológicas de los postulados postmodernistas y, por último, perfilaremos nuestros argumentos desde una perspectiva sociológico-educativa específica hablando de los procesos de socialización y un uso técnológico crítico-ideológico. De modo preciso abogamos por unas actitudes crítico-ideológicas en cuanto al uso tecnológico y su significado desde una óptica de las identidades de género.

Palabras clave: Género, Espistemología, Medios, Nuevas Tecnologías de la información, Socialización.

\section{ABSTRACT}

This paper focuses the meaning of the mass media and of the new technological mass media of the information and communication in relationship to the gender identities under a theoretical-epistemological prism. In a concrete way we will try, first of all, the subjectmatter postmodernism, feminism, mass media and technology. Secondly, we will study in depth the epistemological implications of the postmodernist postulates and, finally, we will outline our arguments from a specific sociological-educational perspective speaking about the processes of socialization and a critically - ideological technological use. In a precise way we advocate a few critical-ideological attitudes as for the technological use and its meaning from an optics of gender identities.

Key words: Gender, Epistemology, Mass Media, New Tecnologies of information, Socialization. 


\section{Introducción}

Esta exposición enfoca el significado de los medios y de los nuevos medios tecnológicos de la información y de la comunicación para las identidades de género bajo un prisma teórico-epistemológico. De modo concreto adoptamos un punto de vista sociológico-educativo de género que centra sus reflexiones, a lo sumo, en una perspectiva epistemológico-teórica que tiene como trasfondo la problemática de los estereotipos de género en la sociedad global e informacional y de las diferencias en función del género que siguen existiendo, si bien, con implicaciones nuevas, en el sistema educativo. Al mismo tiempo profundizamos en una visión empírica acerca de la construcción de las identidades de género a través del universo simbólico de los videojuegos. Tomando como referencia la relevancia social fundamental que se está otorgando a la relación de los sujetos con las nuevas tecnologías de la información y comunicación en la sociedad actual y, si cabe, futura, y las posibilidades e incidencias que se postulan con respecto a la construcción y transformación de las identidades de género femenino y masculino, nos proponemos contribuir a la dilucidación de la presente cuestión enlazando con el amplio debate que está teniendo lugar en el espacio discursivo de las investigaciones de las mujeres y del género en torno a los diversos enfoques-teórico-feministas, postmodernistas y ciberfeministas y su significado para con los procesos de transformación de las identidades y roles de género en la sociedad globalizada e informacional, a la postre, una cuestión clave que se sitúa de lleno en el epicentro del marco temático sociológico-educativo del género.

En esta línea cabe señalar particularmente que a lo largo de los últimos años han hecho aparición teorías que parten de unas posibilidades casí sin limites del uso de internet para la asunción de identidades de género virtuales y de su poder transformativo haciendo especial enfásis en su capacidad de poder descomponer los trazos tradicionales de las identidades de género. Sin embargo, lo que parece evidenciarse en las investigaciones empíricas al respecto es que el uso tecnológico tiene sus impactos en las identidades de género de las y los jóvenes de tal manera que refuerza y socializa unas características diferenciales que aparecen aún en estos momentos como definitorias para las identidades de género femenino y masculino y que no muestran en absoluto una descomposición de los rasgos distintivos de género tradicionales.

Para el empeño en desmenuzar el tema de las nuevas tecnologías y su relación con los procesos de construcción de las identidades de género, se plantéa indagar por tanto, si la concepción teórico-postmoderna de la vida y dinámica alrededor del uso de las nuevas tecnologías, su idea sobre la relatividad en cuanto a las normas y valores sociales, incluso en lo tocante al manejo de la misma tecnología, su aparente neutralidad en relación a las cuestiones más relevantes de la vida social de las personas, tiene realmente unas consecuencias transformador-deconstructivas para con unas nuevas identidades de género, tal y como proclaman las teorías postmodernistas, o si por el contrario lejos de tener esta influencia, las nuevas tecnologías de la información y de la comunicación inciden en unas identidades de género que mantienen unas verticalidades negativas para con el género femenino, o bien que contravienen en realidad abiertamente los postulados de un trato igualitario de los sujetos desde el punto de vista feminista del género y un ángulo epistemológico-crítico-feminista.

De modo concreto acotaremos este extremo ocupandonos, en primer lugar, del anális de la interrelación: postmodernismo, feminismo, medios y tecnología. En segundo lugar, profundizaremos en las implicaciones epistemológicas de los postulados postmodernistas, para perfilar por último, nuestros argumentos desde una perspectiva 
sociológico-educativa específica, si cabe, centrando nuestro foco de atención en los procesos de socialización y de un uso técnológico crítico-ideológico.

\section{1.- Postmodernismo, feminismo, medios y tecnología}

No cabe duda que el panorama teórico feminista se ha ido diferenciando mucho a lo largo de los últimos decenios y que el panorama teórico y epistemológico del pensamiento feminista en estos momentos se presenta sumamente complejo, cada vez más diferenciado, desde una óptica nacional e internacional, hecho que va vislumbrándose especialmente desde finales de los años 80 del siglo XX. En esta época se extiende en el campo general del conocimiento científico, sobre todo social, el debate postmodernista que atrae en cuanto a sus postulados epistemológicos de una crítica radical a las teorías de la Modernidad, al proyecto ilustrado de comprender el sujeto como ser libre, racional, con una identidad c oherente y capaz de descubrir de forma objetiva el orden de las cosas -cometido que se propone precisamente la ciencia moderna-. Este debate seduce asimismo en el contexto teórico feminista, como lo plasman las múltiples aportaciones de autoras tales como Judith Butler (1992), Donna Haraway (1991), Nancy Fraser (1992), Linda Nicholson (1992) y otras. Eso sí, vamos a dejar de lado en este instante indagar hasta qué punto los propios presupuestos postmodernistas son incompatibles con las tesis feministas sobre la emancipación de las mujeres desde nuestro punto de vista. Tal objetivo quedará para la argumentación en un punto posterior, pero el enunciado de Lyotard (1979) "cualquier teoría bien argumentada vale", ya pone de relieve la dirección en la que van las tesis epistemológicas de partida de los planteamientos postmodernistas.

Centrándonos en los enfoques teóricos que suscitan la cuestión de las nuevas tecnologías de la comunicación y de la información, apreciamos como las teorías ciberfeministas otorgan al sujeto un poder performativo y virtual extraordinario. El ciberfeminismo, término introducido por Donna Haraway en 1987, propone a las mujeres una nueva identidad basada en la tecnología como sujetos híbridos y quimeras. Defiende fundamentalmente una visión positiva del uso de las redes, un modelo virtual, para con unas nuevas identidades de las mujeres y del género. Así conceptualiza Sadie Plant (1997) el ciberfeminismo como una cooperación entre mujer, maquina y nuevas tecnologías perfilando el especial vínculo existente de la identidad femenina con la tecnología y el mundo de las. ${ }^{3}$. Algunas teóricas sugieren además una conexión especial entre el cuerpo femenino y la maquina. A estas suposiciones subyace claramente la percepción de que la tecnología o las nuevas tecnologías podrán liberar, por fin, a las féminas de las identidades tradicionales y de las cargas que soporta el cuerpo femenino en la línea de la propuesta hecha por Shulamit Firestone en 1970 con respecto a la sustitución de la maternidad biológica por un utero artificial. Esta última teórica lanza la hipótesis de que la tecnología permitirá liberar a las mujeres de la opresión que se les impone a través de su cuerpo, gracias al desarrollo máximo de la tecnología de la anticoncepción y la reproducción extrauterina.

Al sostener que la división central de la sociedad es la división entre dos sexos como clases, la autora mencionada entiende que la opresión específica de las mujeres está relacionada de manera directa con su biología, con lo cual conceptualizando la desigualdad en términos biológico- naturales propone erradicarla sustituyendo la función biológico maternal por una tecnología que asuma esta función. ${ }^{4}$. Si bien, a pesar de su formulación espectacular, esta concepción asume, de facto, una perspectiva acerca del ser humano que niega a la identidad histórico-colectiva de las mujeres, y con ello a las mujeres, su condición de ser sujeto del proceso social, y, por tanto, comparte en el fondo la óptica 
androcéntrica en cuanto al sujeto humano rechanzando las disposiciones y cualidades psiquico-sociales vinculadas histórico-colectivamente a las mujeres. Desde un ángulo espistemológico sigue la senda del postulado de la superioridad biológico-humana del varón.

Desde su propia argumentación epistemológico-teórica, las propuestas teóricofeministas-tecnologistas subrayan la posibilidad de que las nuevas tecnologías, esencialmente las de la información y de la comunicación, puedan superar los sistemas binarios en relación con las identidades de género y de esta manera contribuir a la eliminación de las diferencias negativas que se constatan para las mujeres. Tales hipótesis requieren, sin duda, una aclaración empírica minuciosa, investigar si tiene correspondencia real este enunciado en lo concerniente a los medios y los nuevos medios tecnológicos, o si por el contrario, las dinámicas mediáticas y tecnológico-informativas encierran significados sociales que remiten a metaforas que proceden y vuelven al espacio de la realidad histórica de las diferencias en función del género de las identidades existentes, o bien, si incluso transmiten los estereotipos tradicionales, a la postre, de forma más acuciante.

La óptica ciberfeminista es, indudablemente, la propuesta lógica de una visión postmoderna en la cual todo planteamiento teórico es relativo e igualmente válido. Asunción Bernárdez hace la apreciación clave que "el ciberfeminismo no se ha liberado a pesar de sus innovadoras propuestas teóricas de la eterna pregunta que ha acuciado al feminismo desde siempre (la cuestión de la subjetividad) ¿Qué es ser mujer?" (BERNÁRDEZ, A., 2005, p.58) y advierte que "hoy día no podemos hablar de feminismo...que no tenga que ver con Internet"(ibdem). Haciéndonos eco de su enunciado y partiendo de la relevancia epistemológica del enfoque teórico-ciberfeminista, formulamos ya en este momento una serie de preguntas que entendemos clave para el contexto que nos ocupa de modo específico en este marco: ¿Quién y quienes están en el espacio del ciberfeminismo? ¿Qué pasa con el colectivo normal de las mujeres y su imagen en el ciberespacio? ¿Es posible realmente calificar a la comunidad virtual una comunidad virtual? ¿No será que en un espacio comunicativo virtual, al estar la capacidad constructiva de la comunicación muy limitada, la categoría genero actuará incluso de forma aún más estereotipada?. A este último peligro alude la autora citada con anterioridad diciendo que "La consecuencia de esto es que en las comunicaciones en la red se produce mucha más homogenidad que en la vida real al respecto al género "(ibdem, p.57).

En definitiva, estos interrogantes han de centrar la aclaración del uso de las nuevas herramientas tecnológicas. Interesa, sobre todo, ver que papel juegan estas últimas en lo referente a los significados en función del género que transmiten, e indagar su poder de socialización en relación con unas supuestas identidades de género nuevas que en realidad son nada más que las viejas identidades estereotipadas en el contexto de un medio tecnológico de nuevo cuño que alienta además la ilusión de situárse fuera de las estructuras del poder androcéntrico. ¿Será cierto que tal y como apuntan ya algunos agudos análisis, que "tanta simulación de identidades y cuerpos ha sido un estímulo muy bueno para la industria del entretenimiento y del ocio", cara a una renovación de las identidades de género?. Por el contrario, ha ayudado a reestablecer la constelación de poderes y la desigualdad. Es más, habrá que pensar incluso en el problema político que se deriva del uso anónimo de la comunicación electrónica que, según subraya literalmente Ana Navarrete (2011): "favoreció la desaparición o desactivación de cualquier acción política transformadora del orden vigente" ${ }^{\text {, }}$, eso si, reconociendo al mismo tiempo la importancia de las reflexiónes sobre el significado crítico de las propias industrias informáticas y sus lenguajes asexuados, así como el uso 
subversivo de los mensajes hegemónicos de internet, por parte de las aportaciones ciberfeministas.

Con todo, queda la duda de que si las supuestas nuevas posibilidades de un activismo político a través de las nuevas tecnologías de la comunicación y de la información puestas de relieve en su momento, como es sabido, por la Cuarta Conferencia Mundial de las Mujeres en ${ }^{7}$, no ha sido una simple quimera e ilusión de colectivos de mujeres pertenecientes ya de por si a circulos político-sociales de elites. Entre otras cosas cada vez más investigaciones hacen especial hincapié en la brecha digital de género en cuanto al uso de las nuevas tecnologías y, según parece, este particular va más allá de un simple significado númerico, esto es, de un uso porcentual más escaso por parte de las mujeres en relación con los varones, cuyas diferencias, por cierto, son cada vez más insignificantes en el segmento de las personas jóvenes. Tiene que ver con una concepción androcéntrica de la propia tecnología, "diseñada por y para hombres"8.

\section{2.- Conocimiento científico neutral y Tecnología de la comunicación}

Para desmenuzar aún más nuestra postura epistemológica, entendemos que necesariamente la investigación de los medios y de las nuevas tecnologías de la información y de la comunicación, de modo especial de su influencia socializadora, tiene que ir más allá de unos planteamientos axiológico neutrales y teórico postmodernistas, más si cabe, desde una óptica epistemológico feminista. Tal perspectiva parte de una crítica de las condiciones vitales actuales, tanto de las mujeres como de los varones, apuesta por "un interés en circunstancias razonables, de la sociedad existente" (1968, p.20-21), asumiendo la definción dada por Max Horkheimer con respecto a la Teoría Crítica de la sociedad ${ }^{9}$, una teoría que incorpora expresamente este interés epistemológico ya que nace de un interés práctico emancipativo de los sujetos femeninos que ni el concepto epistémico moderno análitico puede justificar, ni la convicción postmodernista que defiende, tal y como Fracoise Lyotard lo ha desarrollado, la validez de cualquier teoría, siempre y cuando su argumentación siga las reglas de la lógica y poniendo en duda la válidez de los constructos epistemológicos, teóricos e identitarios del legado teórico-histórico de las Ciencias Sociales.

Aquí reivindicamos la tradición epistemológico-crítico-hermeneútica como la más relevante del panorama epistemológico-científico-social-global-moderno que permite fundamentar las investigaciones empíricas de las relaciones intergénero, y en nuestro caso, el vínculo de los sujetos jóvenes con las nuevas tecnologías y su influencia en las identidades de género, esto es, el ángulo epistemológico-feminista que abanderamos conecta con la línea del paradigma epistemológico-hermeneútico-crítico mencionada ${ }^{10}$. No olvidemos que ciencia da significados; por muy bien argumentada que sea una teoría no se escapa de su vertiente axiológica, solo puede encubrir la misma.

La adopción de un punto de vista teórico-feminista no puede sustentarse en un ángulo epistemológico axiológico-neutral-plural ya que negaría su propia legitimidad metateórica. Es más, el postmodernismo constituye una trampa ideológica del androcentrismo mediante su supuesta crítica radical al modernismo por una parte, y por su negación de los intereses epistemológicos, por otra. Sigue en realidad el paradigma científico moderno en este aspecto y sus postulados epistemológicos. Dicho en otras palabras, no aporta niguna solución al dilema epistmológico de la Ciencia Moderna, dado que sitúa en un mismo plano la legitimidad de todas las propuestas teóricas. Destruye sus axiomas básicos negando la condición socio-histórica de las acciones e identidades humanas que tacha como ideológicas aún cuando está presente en cualquier intento de 
construcción práctica y teórica incluso deconstructivista. Una propuesta de este tipo solo puede tener el mérito de introducir una ampliación de los paradigmas científico-feministas.

La visión teórico-deconstructivista, a la postre una de las posiciones postmodernistas teórico-feministas más conocidas y atractivas por su supuesto potencial de crítica epistemológica radical, pretende resolver, singularmente a través de la contraposición entre corrientes feministas reconstructivistas y deconstructivistas, la cuestión de una nueva conceptualización de las identidades de género. En el plano epistemológico reivindica la necesidad de situarse fuera del contexto de la consideración identitaria del sujeto moderno que postula su coherencia identitaria como tal. La clasificación teórica que apuesta por una óptica deconstructivista no es capaz de desentramar de forma adecuada los significados histórico-sociales de las conceptualizaciones identitarias del género femenino y masculino, ni siquiera desde el propósito específico de un nuevo paradigma y de una posición metafórica que anhela situarse fuera de la concepción heterosexual. Defender:"que las concepciones locales de lo que es "humano", o aún más, que cuales son las condiciones básicas y las necesidades de la vida humana "...deben estar sujetas a reinterpretación, ya que son circunstancias históricas y políticas en que lo "humano" es definido de forma diferente. ${ }^{11}$, significa, a nuestro juicio, situárse de hecho en una línea argumentativa reconstructivista, ya que se incide en la necesidad lógico-sociológica de adaptar las categorías vinculadas a las identidades humanas a los contextos histórico-sociales desde un punto de vista de los elementos concretos que lo conforman. No es necesario, ni lógico remitir aquí a una visión deconstructivista. Ciertamente “...el género es el mecanismo por el cual las nociones de lo masculino y lo femenino son producidas y naturalizadas" (BUTLER, J., 2001, p.22) en el propio contexto de la sociedad, y es allí donde estas nociones de lo femenino y lo masculino son al mismo tiempo reproducidas y renaturalizadas por los propios sujetos, que no son ajenos a este proceso de producción y reproducción. Tal proceso sigue siempre la senda de las dinámicas histórico-sociales, por cuyo motivo no tiene sentido suponer que el género podría ser perfectamente el aparato por el cual tales términos se deconstruyen y desnaturalizan (ibdem, p.22)", ya que el constructo en si ya remite a significados sociales históricamente construidos en la propia práxis social. $\mathrm{Si}$ bien suscribimos que las identidades tradicionales de género precisan de ser modificadas y concebidas en términos abiertos y flexibles, y, por tanto, rechazamos "un discurso restrictivo sobre género, que insiste en el binomio 'hombre' y 'mujer' como vía exclusiva para entender el ámbito del género"(ibdem, p.22)' tal prespectiva no tiene la necesidad de recurrir a la idea de una deconstrucción; de facto, desde un ángulo histórico-social-concreto, los sujetos siempre enlazan con los elementos históricos existentes conocidos o rechazados, si cabe, de las identidades de género, y por consiguiente, reconstruyen y no deconstruyen las nociones y definiciones de lo femenino y lo masculino, esto es, de los géneros.

Desde luego una óptica feminista, tal y como la entendemos aquí, no puede suscribir los postulados epistemológico-postmodernistas que algunas autoras ya califican acertadamente de "...una suerte de nueva racionalidad excluyente..."12. Es obvio que existen propuestas teóricas incompatibles con las exigencias de igualdad de las mujeres, y no solo desde una perspectiva histórico-epistémica. Apoyarse en una argumentación epistemológica de pluralidad, esto es, de la validez epistémica de cualquier propuesta teórica convenientemente argumentada, aniquila de entrada el propio postulado de la igualdad de las mujeres como punto de partida, como a priori epistemológico, del conocimiento de las mujeres y del género. Y esta tesis es ciertamente válida para la investigación de las nuevas tecnologías de la comunicación e información bajo el prisma de las identidades de género. 


\section{3.- Educación, socialización y uso tecnológico crítico-ideológico}

Si bien estamos defendiendo aquí una postura epistemológica crítico-ideológica de las mujeres y del género con respecto a los medios y los nuevos medios tecnológicos, ésta ¿qué significa con vistas a la educación y socialización humana?. En nuestras investigaciones sostenemos la tesis de que los medios de comunicación modernos no solo no son transmisores neutrales de la información desde un punto de vista de la socialización humana, si no que se han convertido en el mecanismo determinante para la reproducción de los estereotipos de género pudiendo aniquilar los efectos de unas políticas que se encaminan decididamente a la consecución de una igualdad en las relaciones intergénero. De manera detallada hemos podido constatar como los medios de la comunicación, especialmente el medio televisivo, ejercen una función ideológicamente regresiva con respecto a las identidades y roles de género femenino y masculino. Refuerzan en la consciencia de las personas, particularmente de las y los jóvenes, los elementos ideológicoandrocéntricos que constituyen la base para el mantenimiento de las estructuras sociales que otorgan a las mujeres de forma preponderante las tareas del cuidado, y en efecto, funciones consideradas irrelevantes y socialmente insignificantes. (RADL PHILIPP, 1995, 2001, 2010, 2011).

En nuestros trabajos y asimismo para el contexto que nos ocupa en este instante aquí adoptamos una concepción teórico-constructivista-interaccionista que pone su particular acento en el poder constructor de los medios de comunicación y tecnológicos y, efectivamente, en el poder socializador resultante de éstos a través de la transmisión de significados. Facilitando las claves para la interpretación del propio significado mediático, los medios de comunicación de masas y las nuevas tecnologías de la información inducen a la construcción de la realidad social circundante.

Enlazando con estas aseveraciones surgen inexorablemente las siguientes preguntas: ¿cómo contrarestar o invertir el efecto socializador descrito?, ¿qué postura adoptar referente al uso de los medios tecnológicos?. Apoyándonos en una visión teóricoconstructivista de los medios en relación con las identidades de género, nuestra posición no puede ser ni de neutralidad, ni de rechazo al uso tecnológico sin que se la pueda tachar por ello de ambigua. Ha de pensarse en una postura proactiva, consciente y de uso crítico en la línea de las argumentaciones que apuestan por la incorporación del uso tecnológico con vistas a unas nuevas identidades de género, eso si, no como un resultado per se y automático vinculado a la misma dinámica tecnológica que emerge, según algunas percepciones, como tal del mero uso de las nuevas tecnológicas.

En este sentido consideramos que se impone la necesidad de un trabajo pausado y detallado de análisis empírico sobre los efectos particulares para poder esbozar un modelo de uso tecnológico diferente a favor de unas identidades de género horizontales e igualitarias que han de partir de modo preciso de los modelos históricos existentes, eso si apuntando a constructos identitarios entrelazados, abiertos y flexibles, contrapuestos a una concepción restrictiva binómica de género. Solo de esta manera es posible superarlos. Asimismo se requiere un trabajo y un quehacer educativo consciente, en definitiva, tomar una actitud crítica ante la simple mayor implantación tecnológica, para lograr por parte de las y los jóvenes usuarias y usuarios lo que denominamos un uso tecnológico-críticoideológico. Esto es, esbozar una dinámica de trabajo educativo que incida en unos procesos de conscienciación que permitan descubrir a las y los propios jóvenes los procesos de construcción de la información y comunicación mediática y sus rasgos 
selectivos en cuanto a las imágenes en función del género que transmiten, así como el significado androcéntrico que comporta tal devenir.

Desde un punto de vista sociológico-educativo nuestra postura incide en la exigencia de la creación de una actitud que fomente en las y los jóvenes un uso consciente de los medios y nuevos medios tecnológicos de la comunicación y de la información, con vistas a las imágenes e identidades de género y prestar especial atención a la percepción de las imágenes, un paso anterior a un uso que pretenda, por ejemplo, una praxis feminista online. ${ }^{13}$.

\section{Conclusiones}

En el marco del texto que constituye el núcleo central de nuestras argumentaciones hemos indagado en la dinámica alrededor del uso de las nuevas tecnologías y su significado en relación con unas nuevas identidades de género. Conectando con las aseveraciones expuestas al respecto, los nuevos medios tecnológicos de la información y de la comunicación junto con los medios de comunicación de masas constituyen, sin duda, las herramientas de reproducción más eficaces para el mantenimiento de las estructuras androcéntricas existentes. Los nuevos medios tecnológicos de la información y de la comunicación manejan de modo preeminente imágenes estereotipadas estando inmersos en la transmisión de imagenes diferenciales en función del género que muestran un falso sobreprotagonismo masculino y correspondientemente un falso subprotagonismo femenino asumiendo de forma sistemática una función ideológico-regresiva para con las identidades de género, según hemos podido confirmar en nuestras investigaciones empíricas sobre el medio televisivo ${ }^{14}$. Los medios mencionados conservan en la consciencia de las personas la noción de que la realidad circundante corresponde eminentemente a una de índole androcéntrica, aún cuando las propias estructuras sociales y de realidad se encuentran ya de hecho en un proceso de modificación y transformación en lo referente a los elementos que definen desde un punto de vista del género los elementos de participación social y de poder dominantes. Para mayor abundamiento observamos un afán ideológico de mantener un dominio masculino en relación con el uso de las nuevas tecnologías puesto que se habla una y otra vez de forma acrítica de la supuesta brecha tecnológica entre mujeres y varones cuando los datos sobre el uso tecnológico y de internet a penas muestran datos significativos con respecto al manejo tecnológico ${ }^{15}$.

Retomando una óptica más teórico-epistemológica, sostenemos que las propuestas teórico-feministas-tecnologistas subrayan especialmente la posibilidad de que las nuevas tecnologías, ante todo las de la información y de la comunicación, puedan contribuir a una superación de los sistemas binarios en relación con las identidades de género y de esta manera abrir nuevas posibilidades identitarias. No obstante, observando las contradicciones teóricas de las propuestas postmodernistas, pensamos que es más relevante abogar desde una óptica identitaria de género por unas actitudes crítico-ideológicas en lo que al uso tecnológico se refiere, sobre todo desde un ángulo de la educación y socialización humana.

\section{Referências}

ANGERER, Ma . L.; DORER, J. Gendered Genres and Gendered Audiences. Genealogie der feministischen Rezeptions-und Fernsehforschung. En: MARCI-BOEHNCKE, G.; WERNER, P.;WISCHERMANN, U. (eds.). Blickrichtung Frauen. Theorien und Methoden geschlechtsspezifischer Rezeptionsforschung. Deutscher Studien Verlag: Weinheim, 1996. 
BERNÁRDEZ, A. Humor y ciberfeminismo. ¿Qué hay de original? En: Dossier Feministes 8. Seminari d` Ínvestigació Feminista. Universitat Jaume I: Castellón, 2005.

BUTLER, J. G.T. Feminism and the subversión of Identity. New York: Roudledge, 1990.

BUTLER, J. Problemas de los género, teoría feminista y discurso psicoanalítico. En:

NICHOLSON, L. J. Feminismo/posmodernismo. Buenos Aires: Feminae, 1992, p.75-95.

. La cuestión de la transformación social. En: BECK-GERNSHEIM, E., B., J.;

PUIGVERT, L. Mujeres y transformaciones sociales. Barcelona: El Roure, 1992, p.7-29.

CABERO, J. Familia y medios de comunicación. Revista Diálogos. n. 233, [s.1]: [s.n.], 2002, p.9-17

Nuevas tecnologías, comunicación y educación. Edutec, Revista Electrónica de Tecnología Educativa (Edutec). n. 1.[s.1]: [s.n],1996.

CASTELLS, M. La era de la información: economía, sociedad y cultura, tomo I, alianza. Madrid: [s.n.], 2005.

FAGOAGA, C. Género, sexo y elites en los medios informativos. En: ORTEGA, F.; FAGOAGA, C. et al: La flotante identidad sexual. Madrid: Instituto de Investigaciones Feministas de la Universidad Complutense/Comunidad de Madrid, 1993.

SCANELLA, P. Umbral de presencia de las mujeres en la prensa española. Madrid: Instituto de la Mujer, 1985.

FIRESTONE, Sh. La dialéctica del sexo. Barcelona: Kairós, 1976.

FRASER, N.; NICHOLSON, L. Crítica social sin filosofía: un encuentro entre el feminismo y el posmodernismo. En: NICHOLSON, L. J. (comp.). Buenos Aires: Postmodernismo, Feminaria, 1992.

HARAWAY, D. Simians, cyborgs and women: the reinvention of nature. London: Free Association London, 1991.

LYOTARD, F. La condición postmoderna: informe sobre el saber. Madrid:Cátedra, 1989. Original en francés: LYOTARD, F. La condition postmoderne: rapport sur le savoir. París: Minuit, 1979.

MARÍN, V.; GARCÍA, M. D. La familia e internet, ¿un juego a tres bandas. [s.1.] Comunicar, n. 21, 2003, p. 123-126.

NAVARRETE T., Ana. Diferentes, desiguales y desconectadas. ¿Quién es quien en las industrias tecnológicas?. En: ASPARKIA. n. 22. [s.1.]: [s.n.], 2011, pág. 23.

NICHOLSON, L .J. Postmodernismo, feminaria. Buenos Aires:

Plant, Sadie, 1992. Ceros más os: mujeres digitales más la nueva tecnocultura. Barcelona: Destino, 1997.

PUENTE, N. Sonia. Activismo y colectivismo en red: praxis feminista on-line y violencia de género. En: ASPARKIA. n. 22, [s.1.]: [s.n.], 2011, p. 85-98.

PUIGVERT, L. Feminismo dialógico: aportaciones de las "otras mujeres" a la transformación social de las relaciones de género. En: BECK-GERNSHEIM, E. Y otras: Mujeres y transformaciones sociales. El Barcelona: El Roure, 2001, p. 31-57. 
RADL PHILIPP, R.: La Nueva identidad del género femenino en los debates de la televisión. En: RADL PHILIPP, R.; GARCÍA NEGRO, M. C. As Mulleres e os Cambios Sociais e Económicos. Santiago de Compostela (Espanha): Universidade de Santiago de Compostela, 1995.

Los medios de comunicación de masas y las imágenes en función del género: sobre la influencia socializadora de la Televisión. En: MUÑOZ, B. (ed.). Medios de comunicación y Cambio Cultural. Madrid: Comunidad de Madrid, 2001.

. Os medios de comunicación como transmisores de violencia simbólica. En: ÁLVAREZ POUSA, L.; PUÑAL RAMA, B. (coord.). Claves para una información non sexista. Santiago de Compostela: Atlántica de Información e Comunicación, 2010, p.83-97.

(ed.). Cuestiones Actuales de Sociología del Género. Madrid: CIS,

2001.

(ed.). A modo de introducción: aspectos epistemológicos de las

investigaciones de las mujeres y del género. En: RADL PHILIPP, R. (ed.) Investigaciones actuales de las mujeres y del género. Santiago de Compostela: Universidade de Santiago de Compostela, 2010.

.Gómez Vázquez, Mª̉ y García Marín, J.Influencia mediática televisiva, dinámica familiar y roles de género: Algunos datos empíricos sobre la situación de los adolescentes. En: RADL PHILIPP, R. (ed.) Cuestiones actuales de sociología del género. Madrid: CIS, 2001.

RADL PHILIPP,R. Acerca del estatus epistemológico-crítico de las investigaciones de género. En: RADL PHILIPP, R.(ed.). Cuestiones actuales de sociología del género. Madrid: CIS, 2001.

Identidades de género, medios y nuevos medios tecnológicos de la comunicación, 2012. En: GARCIA Marín, J. (ed.). Postmodernidade e novas redes sociais: identidades de xénero nos videoxogos. Santiago de Compostela: Universidade de Santiago de Compostela.VAN ZOONEN, L. Feminist Media Studies. London: Sage, 1994.

VÁZQUEZ, Susana; CASTAÑO, Cecilia. La brecha digital de género: práctica de einclusión y razones de exclusión de las mujeres. En: ASPARKIA, n. 22. [s.1.]: [s.n.] 2011.

Notas

\footnotetext{
${ }^{1}$ Este texto já foi publicado em: Bonal, Xavier, Diaz, Capitolina e Luque, David (2013) Conferencia de Sociología de La Educación. La educación en la sociedad global e informacional, ASE, Madrid, ISBN-13: 978-84-695 6587-2, págs. 15-25. Para a publicação nesta revista fizemos algumas mudanças.

${ }^{2}$ Professora do Centro Interdisciplinario de Investigacións Feministas e de Estudos de Xénero (CIFEX). Universidad de Santiago de Compostela. E-Mail: ritam.radl@usc.es

${ }^{3}$ Plant, Sadie (1997) Ceros más os: mujeres digitales más la nueva tecnocultura, Destino, Barcelona. Véase también a Bernárdez, Asunción (2005) Humor y ciberfeminismo. ¿Qué hay de original? En: Dossier Feministes 8, Seminari d` Ínvestigació Feminista, Universitat Jaume I, Castellón, págs. 47 ss.

${ }^{4}$ Véase sobre esta propuesta la obra de Shulamit Firestone donde desarrolla como por fin, cuando la tarea de la reproducción biológica pueda ser asumida por un útero artificial, las mujeres podrán ser libres precisamente por quedar exentos de la carga biológica de la maternidad. Firestone, Shulamit (1976) La dialéctica del Sexo, Kairós, Barcelona.
} 
${ }^{5}$ Navarrete Tudela, Ana (2011) Diferentes, desiguales y desconectadas. ¿Quién es quien en las industrias tecnológicas?, en: ASPARKIA, no. 22, pág. 23.

${ }^{6}$ IBIDEM, pág. 24.

${ }^{7}$ Véase concretamente el compromiso manifestado por parte de la Cuarta Conferencia Mundial de las Mujeres en Beijing, al que también alude Ana Navarrete, 2011, o.c. págs. 25 ss.

${ }^{8}$ Vázquez, Susana y Castaño, Cecilia (2011) La brecha digital de género: práctica de e- inclusión y razones de exclusión de las mujeres, en: ASPARKIA, no. 22, sobre todo págs. 35 y ss. Remito además sobre este tema al libro de Cecilia Castaño (coord.) (2008) La segunda brecha digital, Madrid, Ed. Cátedra, donde presenta la autora los datos de una de las primeras investigaciones sobre el tema en el contexto sociocultural español.

${ }^{9}$ Véase el artículo ya clásico donde este autor introduce la conceptualización de Teoría Crítica frente a la de Teoría Tradicional. Horkheimer, M. (1968) Traditionelle und Kritische Theorie. Fischer, Frankfurt, págs. 20-21, en castellano: Teoría Tradicional y Teoría Crítica. Buenos Aires: Amorrortu, 1974 y Radl Philipp, R. (1996) Sociología crítica. Perspectivas actuales. Madrid: Síntesis, pág.52.

${ }^{10}$ Sobre la argumentación detallada remito a mi aportación: Radl Philipp, R. (2001) Acerca del estatus epistemológico-crítico de las investigaciones de género, en: Radl Philipp, R. (ed.) Cuestiones Actuales de Sociología del Género, CIS, Madrid, págs. 15-27.

${ }^{11}$ Véase Butler, J. (2001) La cuestión de la transformación social, en: Beck-Gernsheim, E., Butler, J. y Puigvert, L.: Mujeres y transformaciones sociales, El Roure, Barcelona, pág. 25. Y Butler, J. (1992) Problemas de los género, teoría feminista y discurso psicoanalítico, en: Nicholson, Linda J.: Feminismo/posmodernismo, Feminae, Buenos Aires, págs. 75-95, y Butler, J. (1990) Gender Trouble. Feminism and the subversion of Identity, Roudledge, New York.

12 Puigvert, Lidia (2001) Feminismo dialógico. Aportaciones de las "otras mujeres" a la transformación social de las relaciones de género. En: Beck-Gernsheim, Elisabeth, Butler, Judith. y Puigvert, Lidia.: Mujeres y transformaciones sociales, El Roure, Barcelona, pág. 39.

13 Existen múltiples proyectos al respecto, aunque pensamos que persiste la gran incógnita si estos movimientos son realmente capaces de transcender su propio "circulo activista" para poder promover de hecho una praxis social más igualitaria. Véase, por ejemplo, Núñez Puente, Sonia (2011) Activismo y colectivismo en red: praxis feminista on-line y violencia de género, en: ASPARKIA, no. 22, págs. 85-98.

${ }^{14}$ Remitimos a los datos publicados sobre la cuestión, por ejemplo: Radl Philipp, R. (2001): Los medios de comunicación de masas y las imágenes en función del género: sobre la influencia socializadora de la Televisión, en: Muñoz, B. (ed.) Medios de comunicación y Cambio Cultural, Comunidad de Madrid, Madrid, y Radl Philipp, R., Gómez Vázquez, Ma B. y García Marín, J. (2001): "Influencia mediática televisiva, dinámica familiar y roles de género: Algunos datos empíricos sobre la situación de los adolescentes" en: Radl Philipp, R. (ed.) Cuestiones Actuales de Sociología del Género, CIS, Madrid, y Radl Philipp, R., Porto Castro, A., Gómez Vázquez, Mª B. y García Marín, J. (2011) Symbolische Gewalt in den Medien, en: KONSENS,, No. 2, pág. 40ss.

15 Radl Philipp, R. (2006). Percepción Social de la Ciencia y la Tecnología y género. En FECYT. Percepción Social de la Ciencia y la Tecnología en España. Madrid: FECYT. Pp. 161-183.

Recebido em abril-2014

Aprovado em maio-2014 